\title{
IMPROVED APPLICATION OF BOMB CARBON IN TEETH FOR FORENSIC INVESTIGATION
}

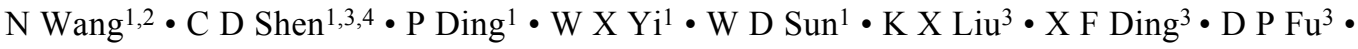

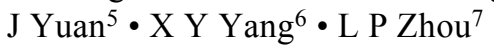

\begin{abstract}
While radiocarbon is widely applied in dating ancient samples, recent studies reveal that ${ }^{14} \mathrm{C}$ concentrations in modern samples can also yield precise ages due to the atmospheric testing of thermonuclear devices between 1950 and 1963. ${ }^{14} \mathrm{C}$ concentrations in both enamel and organic matter of 13 teeth from 2 areas in China were examined to evaluate and improve this method of forensic investigation. Choosing enamel near the cervix of the tooth can reduce the error caused by the difference between the sample formation time and whole enamel formation time because tooth enamel formations take a long time to complete. A proper regional data set will be helpful to get an accurate result when calculating the age of the sample $\left(\mathrm{T}_{1}\right)$ by the CALIBomb program. By subtracting the enamel formation time $(\mathrm{t})$, the birth date of an individual $\left(\mathrm{T}_{2}\right)$ can be confirmed by enamel $\mathrm{F}^{14} \mathrm{C}$ from 2 teeth formed at different ages. Calculated enamel formation dates by ${ }^{14} \mathrm{C}$ concentration are basically consistent with corresponding actual values, with a mean error of $1.9 \mathrm{yr}$ for all results and $0.2 \mathrm{yr}$ for the samples formed after AD 1960. This method is more effective for dating samples completed after AD 1960. We also found that ${ }^{14} \mathrm{C}$ concentrations in organic matter of tooth roots are much lower than atmospheric concentrations in root formation years, suggesting that the organic material keeps turning over even after tooth formation is complete. This might be a potential tool for identification of death age to extract a proper component for ${ }^{14} \mathrm{C}$ dating. We also observed that $\delta^{13} \mathrm{C}$ values between hydroxyapatite and organic matter indicate that isotopic fractionation during the biomineralization is $8-9 \%$ more positive in mineral fractions than in organic matter.
\end{abstract}

\section{INTRODUCTION}

Teeth are one of the best body indexes for recording information about a person in forensic investigation because teeth are the hardest part of the human body and can survive natural decay or artificial chemical treatment (Ritz-Timme et al. 2000). Spalding et al. (2005) previously reported on their work of estimating the birth date of individuals by radiocarbon concentration in enamel, and suggested that ${ }^{14} \mathrm{C}$ in modern teeth can be used in forensic investigations. However, details such as dental background, calculation method, selection of feasible results, and other informative points related to this method were not provided; these points are discussed here as background pertaining to our research.

Teeth have 3 parts to their external morphology (the crown, cervix, and root) and consist of 4 material types: enamel, dentine, cementum, and dental pulp (Figure 1). Enamel is mainly composed of mineral $\left(\sim 96 \%\right.$ hydroxyapatite, $\left.\mathrm{Ca}_{10}\left(\mathrm{PO}_{4}\right)_{6}(\mathrm{OH})_{2}\right)$, and the ${ }^{14} \mathrm{C}$ concentration in enamel represents the atmospheric levels at the time when the enamel is formed (Mays 1999). Dentin is made up of $30 \%$ organic matter and $70 \%$ mineral. Unlike enamel, dentin continues exchanging with the body metabolism even after the tooth formation is complete. This renewal characteristic could make dentin organic material a good record of metabolic activity up to the time of death. In a lifetime, human dental formation includes deciduous teeth and permanent teeth. Every tooth has 10 stages of development as described by Nolla (1960) (see Figure 2).

${ }^{1}$ Key Lab of Isotope Geochronology and Geochemistry, Guangzhou Institute of Geochemistry, Chinese Academy of Sciences, Guangzhou 510640, China.

${ }^{2}$ Department of Earth Sciences, University of Hong Kong, Hong Kong.

${ }^{3}$ State Key Lab of Nuclear Physics and Technology, Peking University, Beijing 100871, China.

${ }^{4}$ Corresponding author. Email: cdshen@gig.ac.cn.

${ }^{5}$ Medical College, Jinan University, Guangzhou 510630, China.

${ }^{6}$ School of Earth and Space Sciences, University of Science and Technology of China, Hefei 230026, China.

${ }^{7}$ Laboratory for Earth Surface Processes, Department of Geography, Peking University, Beijing 100871, China.

C 2010 by the Arizona Board of Regents on behalf of the University of Arizona

Proceedings of the 20th International Radiocarbon Conference, edited by A J T Jull

RADIOCARBON, Vol 52, Nr 2-3, 2010, p 706-716 


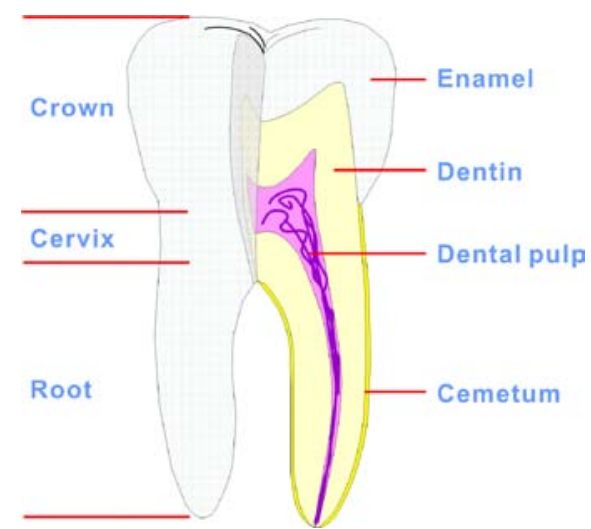

Figure 1 Structure and composition of a tooth (Cate 1998)

(1) In Inial dental sac
(2) Initial Crown Formation
(3) Crown $\frac{1}{3}$ Complete
(4) Crown $\frac{2}{3}$ Complete
(5) Crown nearly Complete
(6) Crown Complete
(1) Root Complete
(1) Root $\frac{1}{3}$ Complete $\frac{2}{3}$ Complete
(1) Apex Closure Complete

Figure 2 Tooth development rating system (Nolla 1960) 
In permanent teeth, enamel formation begins at the crown (stage 3, Figure 2) and continues downward to the cervix junction (stages 4-6, Figure 2) (Nolla 1960; Hillson 1986); the difference in the incorporated atmospheric ${ }^{14} \mathrm{C}$ value in the crown versus the cervix enamel formation may thus be offset by up to $6 \mathrm{yr}$ (Reid and Dean 2006). Therefore, cervix enamel could provide a ${ }^{14} \mathrm{C}$ result closer to an individual's actual age because this portion is formed near the time when enamel formation is complete. Another consideration in sample selection is the growth sequence and eruption of permanent teeth (Schour and Massler 1940). In Table 1, enamel formation time means the owner's age when the whole enamel is formed (stage 6), while root formation time (stage 9) is generally near the age when the whole tooth is finished.

Table 1 The growth sequence of permanent teeth (after Schour and Massler 1940).

\begin{tabular}{|c|c|c|c|c|c|c|c|c|}
\hline \multirow[b]{2}{*}{ Type of tooth } & \multicolumn{4}{|c|}{ Upper teeth } & \multicolumn{4}{|c|}{ Lower teeth } \\
\hline & $\begin{array}{l}\text { Initial } \\
\text { hard issue } \\
\text { formation }\end{array}$ & $\begin{array}{l}\text { Enamel } \\
\text { formation } \\
(\mathrm{yr})\end{array}$ & $\begin{array}{l}\text { Erup- } \\
\text { tion } \\
(\mathrm{yr})\end{array}$ & $\begin{array}{l}\text { Root } \\
\text { formation } \\
(\mathrm{yr})\end{array}$ & $\begin{array}{l}\text { Initial } \\
\text { hard issue } \\
\text { formation }\end{array}$ & $\begin{array}{l}\text { Enamel } \\
\text { formation } \\
(\mathrm{yr})\end{array}$ & $\begin{array}{l}\text { Erup- } \\
\text { tion } \\
(\mathrm{yr})\end{array}$ & $\begin{array}{l}\text { Root } \\
\text { formation } \\
(\mathrm{yr})\end{array}$ \\
\hline Central incisor & 3 4 months & & $7 \sim 8$ & 10 & 3 4 months & $4 \sim 5$ & $6 \sim 7$ & 9 \\
\hline Lateral incisor & $10 \sim 12$ months & $4 \sim 5$ & $8 \sim 9$ & 11 & 3 4 months & $4 \sim 5$ & $7 \sim 8$ & 10 \\
\hline Canine & 4 5 months & $6 \sim 7$ & $11 \sim 12$ & $13 \sim 15$ & 4 5 months & $6 \sim 7$ & $9 \sim 10$ & $12 \sim 14$ \\
\hline First premolar & $1.5 \sim 1.75 \mathrm{yr}$ & $5 \sim 6$ & $10 \sim 11$ & $12 \sim 13$ & $1.75 \sim 2 \mathrm{yr}$ & $5 \sim 6$ & $10 \sim 12$ & $12 \sim 13$ \\
\hline Second premolar & $2 \sim 2.25 \mathrm{yr}$ & $6 \sim 7$ & $10 \sim 12$ & $12 \sim 14$ & $2.25 \sim 2.5 \mathrm{yr}$ & $6 \sim 7$ & $11 \sim 12$ & $13 \sim 14$ \\
\hline First molar & $0 \mathrm{yr}$ & & $6 \sim 7$ & & & $2.5 \sim 3$ & $6 \sim 7$ & $9 \sim 10$ \\
\hline & & & & & & 7 8 & $11 \sim 13$ & \\
\hline Third molar & $7 \sim 9 \mathrm{yr}$ & & & & $8 \sim 10 \mathrm{yr}$ & $12 \sim 16$ & $17 \sim 21$ & $18 \sim 25$ \\
\hline
\end{tabular}

"Bomb carbon" ${ }^{14} \mathrm{C}$ chronologies are the basis of ${ }^{14} \mathrm{C}$ application in modern forensic investigations. Compared to the traditional ${ }^{14} \mathrm{C}$ chronology more commonly used in applications such as archaeology, modern atmospheric ${ }^{14} \mathrm{C}$ concentration increased dramatically during the artificial nuclear test activities of the 1950s and early 1960s (Figure 3; Stuiver et al. 1998; data from Hua and Barbetti 2004), with the atmospheric ${ }^{14} \mathrm{C}$ concentration approaching nearly twice the pre-bomb levels. These values of ${ }^{14} \mathrm{C}$ in the atmosphere were transferred into the biosphere through the biogeochemical cycle (de Vries 1958; Nydal and Lövseth 1965). As a result of the 1963 Nuclear Test Ban Treaty, atmospheric ${ }^{14} \mathrm{C}$ concentration began to decline at a rate much faster than natural ${ }^{14} \mathrm{C}$ radioactive decay due to fossil carbon dilution and oceanic and biospheric absorption (Broecker et al. 1959; Nydal and Lövseth 1965; Harkness and Walton 1969; Nydal et al. 1971). Atmospheric values of contemporary ${ }^{14} \mathrm{C}$ are incorporated into the biosphere, and all things living in this post-bomb period mirror the values of the contemporary atmosphere (Levin and Kromer 2004).

We also considered regional variation of post-bomb atmospheric values of ${ }^{14} \mathrm{C}$. Regional records of modern ${ }^{14} \mathrm{C}$ in the atmosphere in the past $50 \mathrm{yr}$ indicate 4 different zones are found according to different variations in the record (Figure 4). As Figure 3 shows, values and positions of bomb ${ }^{14} \mathrm{C}$ peaks in those 4 zones are quite different from each other before 1970, while curves are almost the same after 1970 (Hua and Barbetti 2004). We suggest that for forensic work, choosing a proper regional data set relative to the sampling site is necessary to give a precise ${ }^{14} \mathrm{C}$ age in modern ${ }^{14} \mathrm{C}$ chronology.

In Figure 4, for example, a world map shows the partition of modern atmospheric ${ }^{14} \mathrm{C}$ concentrations into 4 zones, based on "bomb carbon" ${ }^{14} \mathrm{C}$ recorded in tree rings (Hua and Barbetti 2004). The regional differentiation is a result of atmospheric circulation patterns that influenced the diffusion of high ${ }^{14} \mathrm{C}$ concentration from nuclear test sites in the Pacific Ocean. The squares in Figure 4 indicate our study sites, which are located in Northern Hemisphere zone 3 (NH 3). Thus, we use the data of $\mathrm{NH} 3$ to calculate the ${ }^{14} \mathrm{C}$ ages of our samples. 


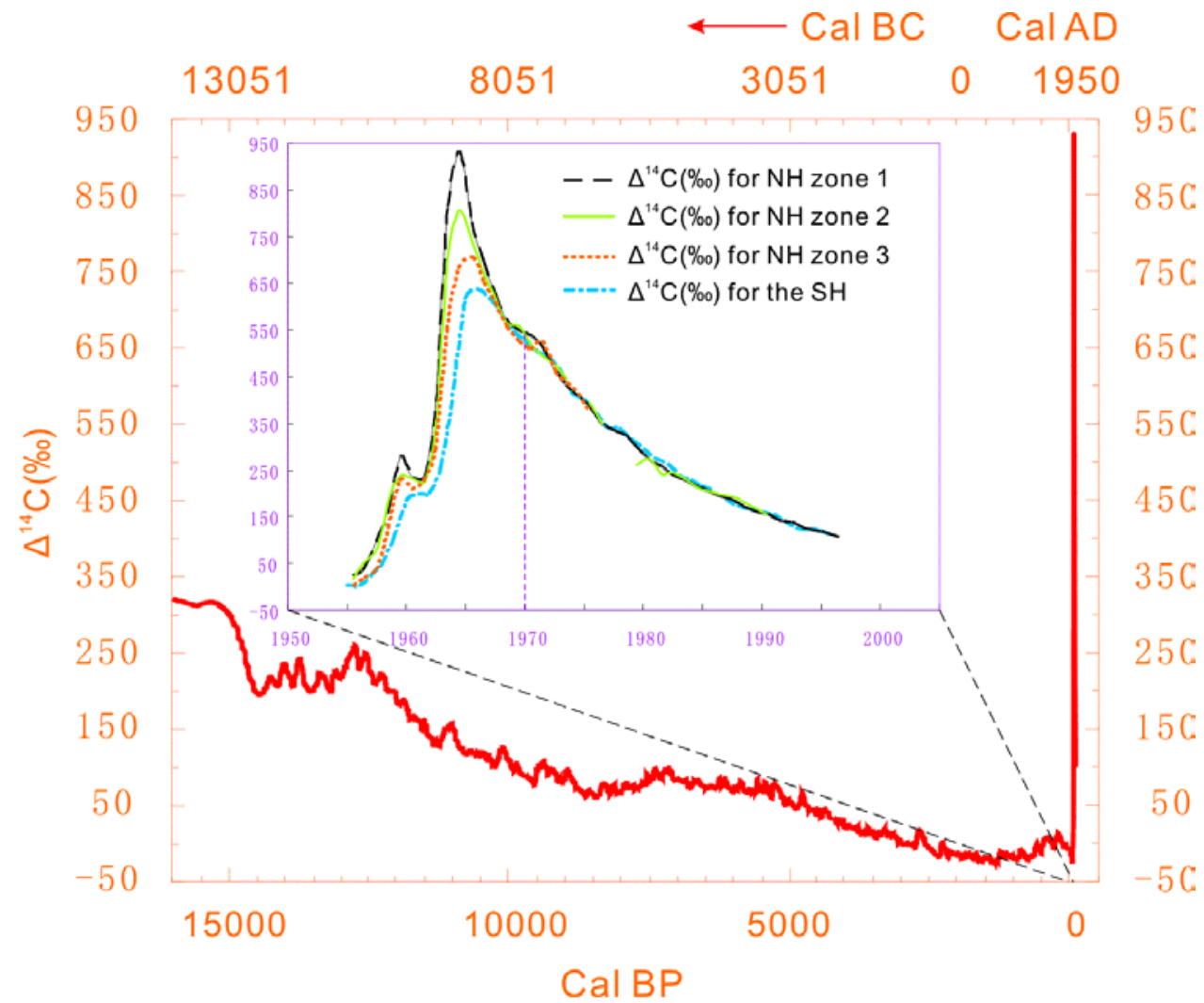

Figure $3{ }^{14} \mathrm{C}$ variation in the atmosphere since $15,000 \mathrm{cal}$ BP (Stuiver et al. 1998) and different records of bomb ${ }^{14} \mathrm{C}$ in 4 zones all over the world (Hua and Barbetti 2004).

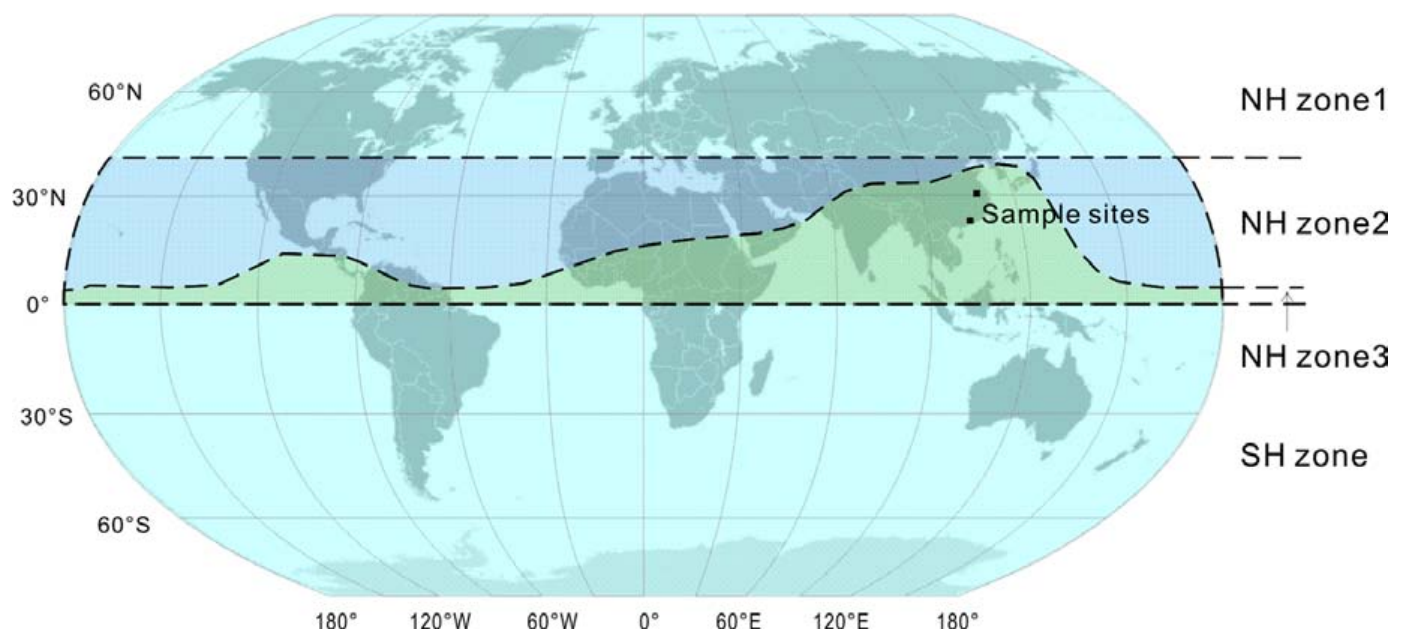

Figure 4 Four different ${ }^{14} \mathrm{C}$ zones around the world (after Hua and Barbetti 2004) 
Modern ${ }^{14} \mathrm{C}$ concentration is usually presented in the form $\mathrm{F}^{14} \mathrm{C}$, which is defined in the following function (Stuiver and Polach 1977; Reimer et al. 2004):

$$
\mathrm{F}^{14} \mathrm{C}=\mathrm{A}_{\mathrm{SN}} / \mathrm{A}_{\mathrm{ON}}
$$

This value is generally used to report ${ }^{14} \mathrm{C}$ data after $\mathrm{AD} 1950$. Using the $\mathrm{F}^{14} \mathrm{C}$ values for the zone from which a set of samples comes, the program CALIBomb (http://calib.qub.ac.uk/CALIBomb) can be used to calculate ages of modern samples (Stuiver and Reimer 1993; Levin and Kromer 2004; Reimer et al. 2004).

\section{SAMPLES AND METHODS}

In late 2006 and early 2007, a total of 13 teeth samples were collected from Guangzhou ( $n=9$ teeth; sample identifications beginning with MT) and Bangbu ( $n=4$ teeth; sample identifications beginning with TB) in China. Samples MT-1\&MT-2, MT-3\&MT-4, and MT-8\&MT-9 are each from 3 people. The 2 sites are shown as black squares in Figure 4, and the geographic locations are $113^{\circ} 17^{\prime} \mathrm{E}, 23^{\circ} 8^{\prime} \mathrm{N}$ for Guangzhou and $117^{\circ} 12^{\prime} \mathrm{E}, 32^{\circ} 57^{\prime} \mathrm{N}$ for Bangbu, respectively. Teeth samples were supplied by dentists in Guangzhou Huaqiao Hospital and Bangbu People's Hospital.

The teeth samples were divided into 2 parts from the cervix line and the crown and root. The crown part was pretreated following Spalding's method to get pure hydroxylapatite (Spalding et al. 2005), while the root part was decalcified to retain only the organic matter. Treatment details are as follows.

Both the crown and root parts were carefully cleaned by $\mathrm{DDH}_{2} \mathrm{O}$ (double-distilled water) to exclude remains of gingival tissue. The crown part was then immersed in $10 \mathrm{~N} \mathrm{NaOH}$ for several hours at room temperature, then in an ultrasound bath overnight with the temperature gradually increasing to $70^{\circ} \mathrm{C}$. After the bath, some soft issue was corroded and very easy to pry out. After rinsing the original tooth sample with $\mathrm{DDH}_{2} \mathrm{O}$, successive baths with fresh $10 \mathrm{~N} \mathrm{NaOH}$ solution were repeated for 10 days until only pure hard enamel remained. The enamel was carefully washed by $\mathrm{DDH}_{2} \mathrm{O}$, then dried at $65^{\circ} \mathrm{C}$. The enamel was then etched in $0.25 \mathrm{~N} \mathrm{HCl}$ for $10 \mathrm{~min}$ to remove possible pedogenic carbonate. The enamel was then rinsed 3 times by $\mathrm{DDH}_{2} \mathrm{O}$ and dried at $65^{\circ} \mathrm{C}$. About $200 \mathrm{mg}$ from the chemically treated cervix enamel was put in a special carbonate reaction tube with orthophosphoric acid. After a standard carbonate reaction procedure, purification, and graphitization (Xu et al. 2007), the graphite target was analyzed at the Peking University accelerator mass spectrometry (AMS) laboratory (Liu et al. 2007).

The chemical treatment for tooth root samples isolated the organic material in dentine. The root was placed in $2 \mathrm{~N} \mathrm{HCl}$ at room temperature for several hours until all minerals were dissolved and only the soft resilient issue remained. This insoluble material was rinsed 3 times in $\mathrm{DDH}_{2} \mathrm{O}$, then immersed in $0.5 \mathrm{~N} \mathrm{HCl}$ for another $10 \mathrm{hr}$. This tooth material was rinsed, centrifuged, and freezedried. The dried organic sample was placed in a quartz reaction tube with $\mathrm{CuO}$ and silver for combustion to $\mathrm{CO}_{2}$, then the $\mathrm{CO}_{2}$ cryogenically purified and graphitized. If there was $\mathrm{CO}_{2}$ in excess of requirements for the graphite target, the excess was collected for ${ }^{13} \mathrm{C}$ analysis at State Key Laboratory of Loess and Quaternary Geology in Xi'an. As with the enamel samples, the graphite target for dentin was sent to the Peking University AMS lab for analysis.

\section{RESULTS}

All measurement results of ${ }^{14} \mathrm{C}$ and stable carbon isotopes in teeth are listed in Table $2 .{ }^{14} \mathrm{C}$ concentrations are expressed in $\mathrm{F}^{14} \mathrm{C}$, while stable carbon isotope contents are given in $\delta^{13} \mathrm{C}$ (VPDB, \%o). 


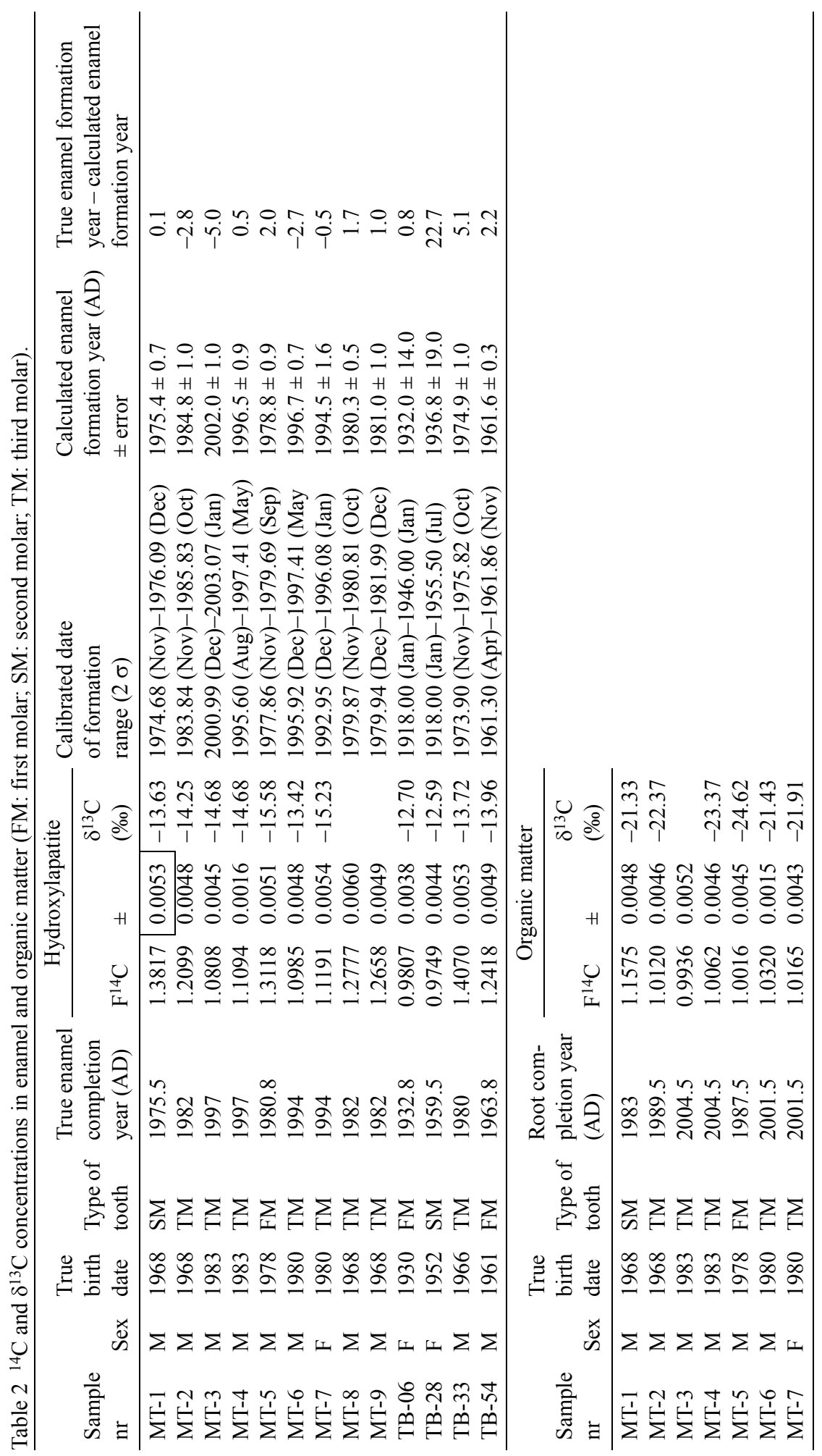


Ages $\left(T_{1}\right)$ of samples formed after 1950 can be calculated by CALIBomb using the $\mathrm{F}^{14} \mathrm{C}$ value. According to the regional ${ }^{14} \mathrm{C}$ data set, CALIBomb can compute the age range $\left(\mathrm{T}_{1}\right)$ of samples with a $\mathrm{F}^{14} \mathrm{C} \pm$ error. Since ${ }^{14} \mathrm{C}$ concentration in the atmosphere fell after rising in the last $60 \mathrm{yr}$, there are 2 age ranges for $1 \mathrm{~F}^{14} \mathrm{C}$ value, before and after the atmospheric $\mathrm{F}^{14} \mathrm{C}$ peak, respectively, like MT-1 (lighter regions) shown in Figure 5. The $\mathrm{F}^{14} \mathrm{C}$ of MT-1 is $1.3817 \pm 0.0053$, and there are 2 age ranges (AD 1974.7 1976.1 and 1962.7 1963.1) that have this $\mathrm{F}^{14} \mathrm{C}$ value. To choose the best date, another tooth having a different enamel formation time from the same person needs to be tested. Thus, MT2, a third molar from the same person, was taken for ${ }^{14} \mathrm{C}$ analysis. With a $\mathrm{F}^{14} \mathrm{C}$ value of $1.2099 \pm$ 0.0048, we get 2 age ranges of MT-2 (darker regions): AD 1959.2 1961.3 and 1983.9 1985.8. The growth sequence of human teeth is known, so the rational pair of results is easy to find by comparing the sequence of calculated ages. We know that the third molar grows $\sim 8$ yr later than the second molar (Table 1), so it is reasonable that MT-1 was formed in AD 1974.7 1976.1 ( $\mathrm{T}_{1}$ for MT-1, dashed line with arrow) while MT-2 was completed during 1983.9 1985.8 ( $\mathrm{T}_{1}$ for MT-2). After getting the right enamel formation date $T_{1}$, we can calculate the birth date $T_{2}$ (dotted line in Figure 5) of the tooth's owner by subtracting the age ( $t$, solid line in Figure 5) when the enamel is formed. Val-

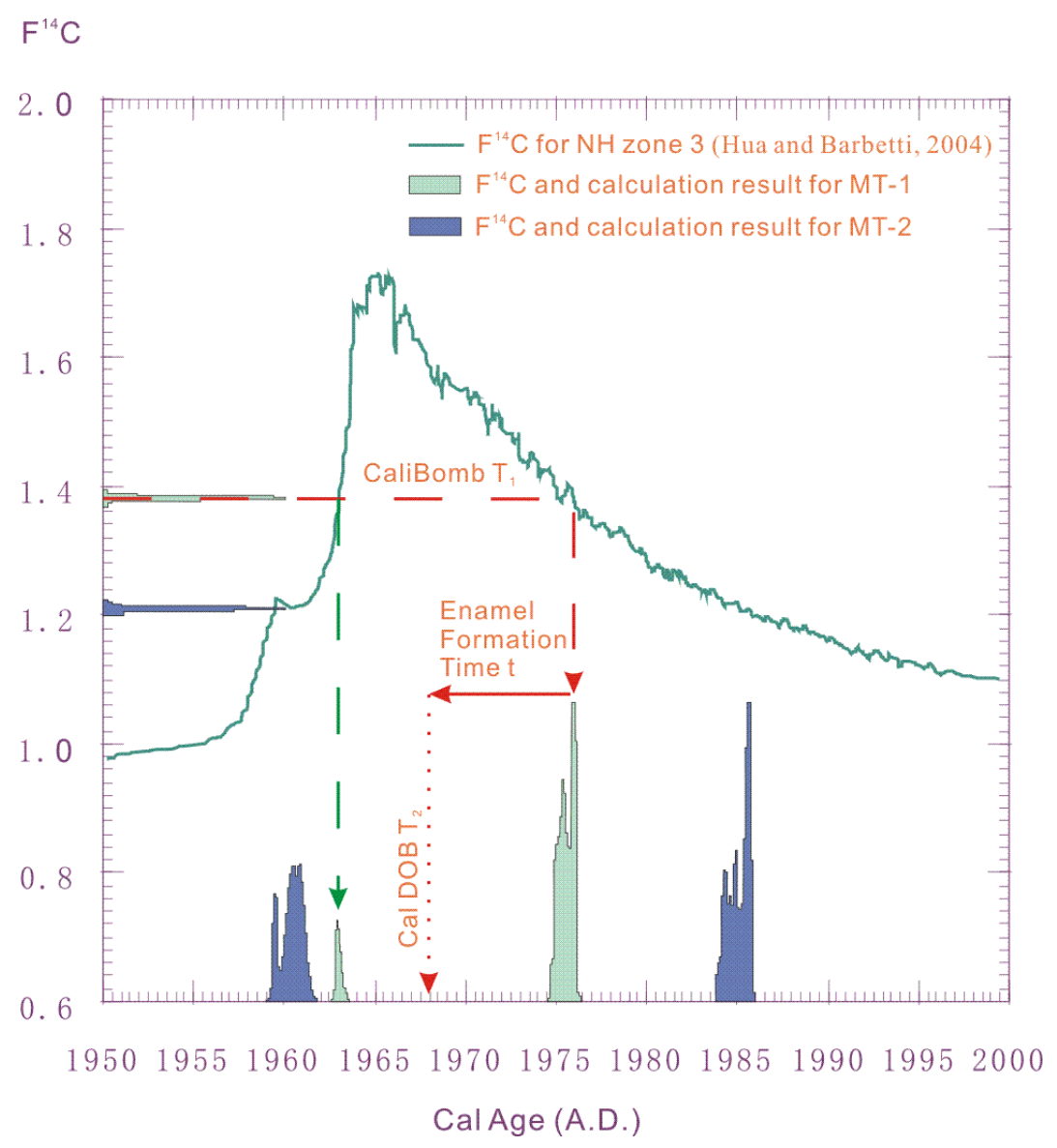

Figure 5 Birth date calculations for samples MT-1 (lighter area) and MT-2 (darker area). Arrows point to the calculation process. The dashed line shows calculation results for sample formation date $\left(\mathrm{T}_{1}\right)$, the solid line is the enamel formation time $(\mathrm{t})$, and the dotted line shows the calculation date of birth $\left(\mathrm{T}_{2}\right)$. 
ues of $\mathrm{t}$ for MT-1 and MT-2 are 7.5 and $14 \mathrm{yr}$, respectively (Table 1). Therefore, the birth date $\mathrm{T}_{2}$ ranges of the owner are AD 1967.2 1968.6 and 1969.9 1971.8 based on MT-1 and MT-2, respectively. The calculation process is indicated by the arrows in Figure 5.

The relationship between the calculated age and actual age of enamel is the same as the one between the calculated and actual birth date, only without a subtraction of enamel formation time. So, to evaluate this dating method, calculated and actual enamel ages are used in Figure 6 instead of the traditional birth date data. We converted the calibrated date range (in Table 2) into a year value with an error (Figure 6). This error is much larger for samples formed before 1960 than those after 1960. The dotted line shows the situation where the calculated result is equal to the actual date. Figure 6 shows a good consistency between most calculated results and corresponding enamel age of known-age teeth. This in turn means good agreement between the calculated and actual birth dates. The average error of ${ }^{14} \mathrm{C}$ dating results is $1.9 \mathrm{yr}$ (the mean value of "true enamel formation year" minus the "calculated enamel formation year" in Table 2).

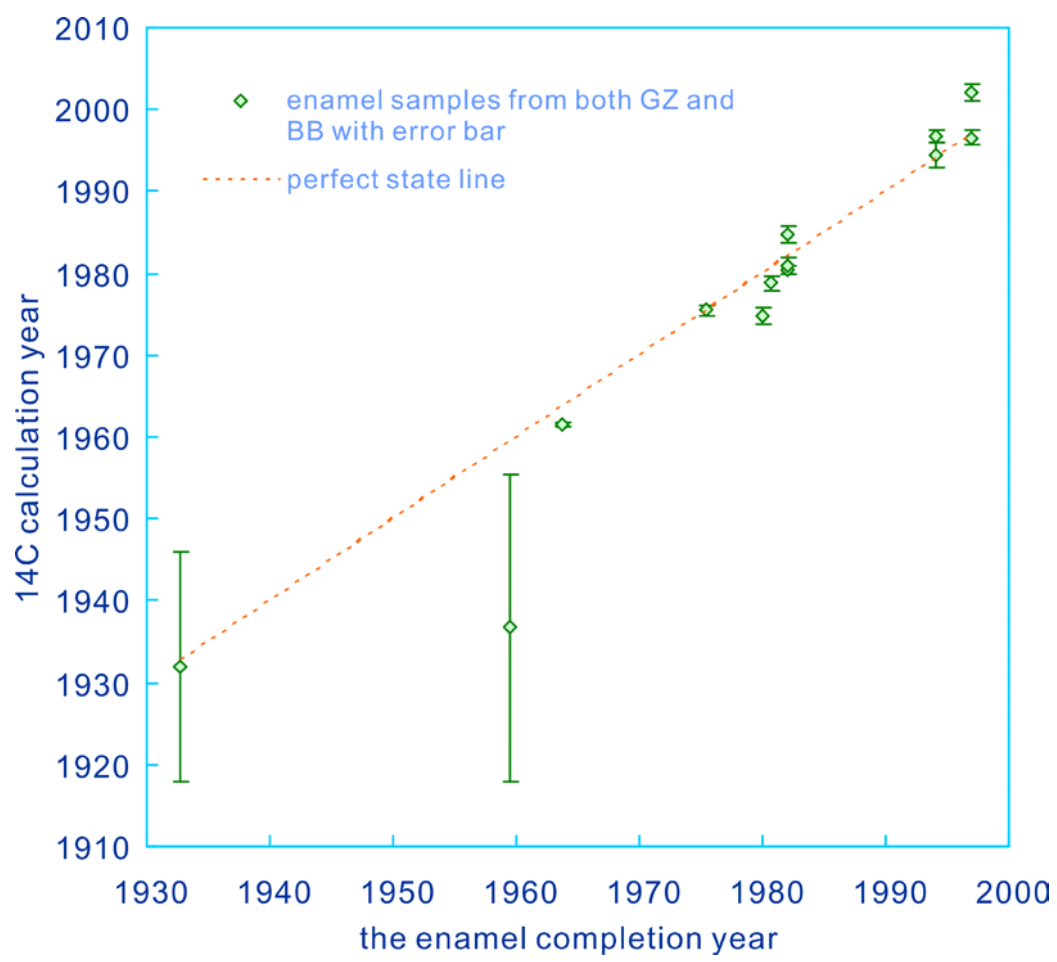

Figure 6 Comparison of calculated results and true enamel formation dates

${ }^{14} \mathrm{C}$ concentrations in tooth organic matter are also presented in Figure 7. Unlike the $\mathrm{F}^{14} \mathrm{C}$ of enamel, ${ }^{14} \mathrm{C}$ concentrations of tooth organic matter are obviously lower than the atmospheric ${ }^{14} \mathrm{C}$ concentrations at the time when tooth root formation is complete. Most organic $\mathrm{F}^{14} \mathrm{C}$ results are close to 1.01, except 1 point that is much higher than the others. Even this odd sample has a lower content, implying that it formed after the formation of the root. 


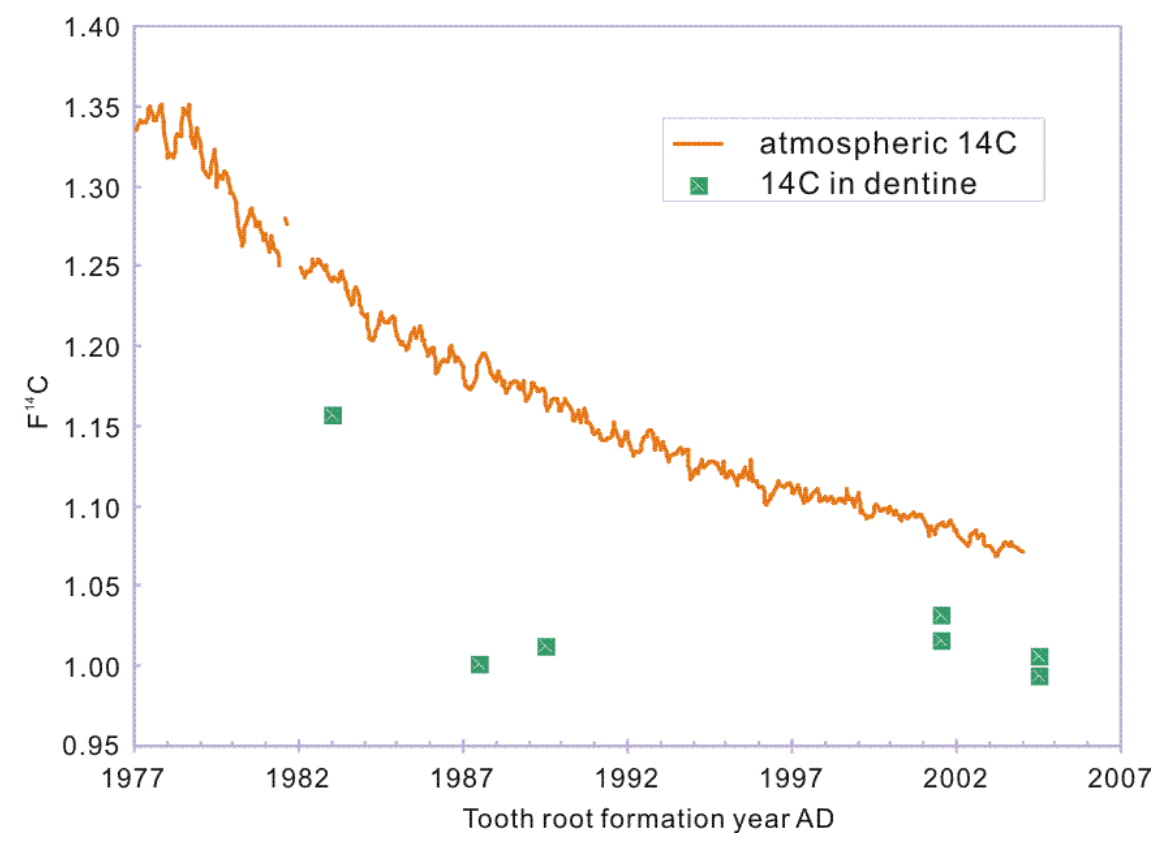

Figure $7{ }^{14} \mathrm{C}$ concentrations in tooth organic matter

\section{DISCUSSION AND CONCLUSIONS}

${ }^{14} \mathrm{C}$ in teeth is a useful record for forensic investigations. We tried to improve the application of bomb ${ }^{14} \mathrm{C}$ in teeth both from the dentology perspective and that of modern ${ }^{14} \mathrm{C}$ chronology. To get the most precise age of an object, we should pay attention to 3 points:

First, enamel near the tooth cervix will give a result closer to the enamel formation year since the cervix is generally the last part to be formed. Due to the development of the $\mathrm{AMS}{ }^{14} \mathrm{C}$ technique, we can date a small amount of sample containing only several hundreds of micrograms of carbon, enabling the analysis of a small fragment of enamel. Given the chance, we need to make a good selection of the proper part to sample. As mentioned, the formation of enamel requires a long time to complete. For the enamel formation time, we calculated the age when the whole enamel is complete. The last formed part will give a more accurate age by this method. Since the enamel grows from the cusp on the top of the crown and continues downward to the cervix, the part near the cervix is the last formed part of the enamel.

Secondly, 2 teeth formed at different ages from an object are necessary to cross-check the date from the CALIBomb results. We have explained that $1 \mathrm{~F}^{14} \mathrm{C}$ value will generate 2 possible age ranges before and after the atmospheric ${ }^{14} \mathrm{C}$ peak. It is not easy to distinguish the best range to use. An example was shown to explain how dating 2 teeth solved this problem. Considering the shorter time ranges of enamel formation, we prefer to use the first molar and second molar as analysis samples.

Thirdly, it is important to choose the proper regional ${ }^{14} \mathrm{C}$ data set relative to the area from where the sample comes. According to modern ${ }^{14} \mathrm{C}$ records all over the world, atmospheric ${ }^{14} \mathrm{C}$ concentrations vary according to the different zones, especially during the period AD 1955 1975. Dating a sample formed in this time range would give different results according to different regional data sets. It is therefore necessary to take this point into consideration. 
$\mathrm{F}^{14} \mathrm{C}$ in enamel from 2 different areas in China is measured to give a reliable birth date of the object (Figure 6). Samples formed before AD 1960 yield greater errors, while results of samples formed after 1960 are closer to the dotted line. Accurate dating is limited to samples formed after 1960. This may be because ${ }^{14} \mathrm{C}$ concentration changed dramatically after the 1960 s due to nuclear bomb testing. The same AMS ${ }^{14} \mathrm{C}$ analysis error will correspond to a much narrower date range when compared to one from a period with stable ${ }^{14} \mathrm{C}$ content, which could generate a large range of possible ages.

Our ${ }^{14} \mathrm{C}$ dating of organic material from teeth roots revealed that the organic material formed much later than the root formation time. Most had similar ${ }^{14} \mathrm{C}$ concentration, except 1odd point. Given that our samples are teeth extracted due to dental disease, some cacodontia may stop exchanging with the body before extraction due to the dental disease, generating this exceptional point. In many previous studies, dentine from the crown was used for dating by aspartic acid racemization. This part of dentin does not change or turnover after it is formed (Helfman and Bada 1976; Ogino et al. 1985). However, the dentin of the root part has quite different characteristics because of the formation of secondary dentin. Secondary dentin is dentin formed after root formation is complete. It usually deposits around the pulp chamber, which mainly belongs to the tooth root. Cook et al. (2006) found that the ${ }^{14} \mathrm{C}$ concentration in their root collagen was similar to the later atmospheric record after the root formation. The organic material in our study has a lower $\mathrm{F}^{14} \mathrm{C}$ concentration relative to its associated enamel, indicating that organic matter in roots has a continual turnover during the lifetime of the individual. Further work will emphasize identifying the exact component in root organic material that would give a high-precision date of death age.

\section{ACKNOWLEDGMENTS}

This work was funded by the National Natural Science Foundation of China grants 40231015 and 40473002, as well as grants 2005CB422004 and KSCX2-SW-133 from the National Basic Research Program of China and the Knowledge Innovation Program of the Chinese Academy of Sciences, respectively.

\section{REFERENCES}

Broecker WS, Schulert A, Olson EA. 1959. Bomb carbon-14 in human beings. Science 130(3371):331-2.

Cate AR Ten. 1998. Oral Histology: Development, Structure, and Function. 5th edition. Toronto: Mosby-Year Book. 150 p.

Cook GT, Dunbar E, Black SM, Xu S. 2006. A preliminary assessment of age at death determination using the nuclear weapons testing ${ }^{14} \mathrm{C}$ activity of dentine and enamel. Radiocarbon 48(3):305-13.

de Vries H. 1958. Atomic bomb effect: variation of radiocarbon in plants, shells, and snails in the past 4 years. Science 128(3318):250-1.

Harkness DD, Walton A. 1969. Carbon-14 in the biosphere and humans. Nature 223(5212):1216-8.

Helfman PM, Bada JL. 1976. Aspartic acid racemisation in dentine as a measure of ageing. Nature 262(5566): 279-81.

Hillson S. 1986. Teeth. Cambridge: Cambridge University Press. 376 p.

Hua Q, Barbetti M. 2004. Review of tropospheric bomb ${ }^{14} \mathrm{C}$ data for carbon cycle modeling and age calibration purposes. Radiocarbon 46(3):1273-98.
Levin I, Kromer B. 2004. The tropospheric ${ }^{14} \mathrm{CO}_{2}$ level in mid-latitudes of the Northern Hemisphere (19592003). Radiocarbon 46(3):1261-72.

Liu KX, Ding XF, Fu DP, Pan Y, Wu XH, Guo ZY, Zhou LP. 2007. A new compact AMS system at Peking University. Nuclear Instruments and Methods in Physics Research B 259(1):23-6.

Mays S. 1999. The Archaeology of Human Bones. New York: Routledge. 242 p.

Nolla CM. 1960. The development of permanent teeth. Journal of Dentistry for Children 27:254-66.

Nydal R, Lövseth K. 1965. Distribution of radiocarbon from nuclear tests. Nature 206(4988):1029-31.

Nydal R, Lövseth K, Syrstad O. 1971. Bomb ${ }^{14} \mathrm{C}$ in the human population. Nature 232(5310):418-21.

Ogino T, Ogino H, Nagy B. 1985. Application of aspartic acid racemization to forensic odontology: post mortem designation of age at death. Forensic Science International 29(3-4):259-67.

Reid DJ, Dean MC. 2006. Variation in modern human enamel formation times. Journal of Human Evolution 50(3):329-46. 
Reimer PJ, Brown TA, Reimer RW. 2004. Discussion: reporting and calibration of post-bomb ${ }^{14} \mathrm{C}$ data. Radiocarbon 46(3):1299-304.

Ritz-Timme S, Cattaneo C, Collins MJ, Waite ER, Schutz HW, Kaatsch H-J, Borrman HIM. 2000. Age estimation: the state of the art in relation to the specific demands of forensic practise. International Journal of Legal Medicine 113(3):129-36.

Schour I, Massler M. 1940. Studies in tooth development - the growth pattern of human teeth. Part II. Journal of the American Dental Association 27:191831.

Spalding KL, Buchholz BA, Bergman LE, Druid H, Frisen J. 2005. Age written in teeth by nuclear tests. Nature 437(7057):333-4.
Stuiver M, Polach HA. 1977. Discussion: reporting of ${ }^{14} \mathrm{C}$ data. Radiocarbon 19(3):355-63.

Stuiver M, Reimer PJ. 1993. Extended ${ }^{14} \mathrm{C}$ data base and revised CALIB $3.0{ }^{14} \mathrm{C}$ age calibration program. $R a$ diocarbon 35(1):215-30.

Stuiver M, Reimer PJ, Bard E, Beck JW, Burr GS, Hughen KA, Kromer B, McCormac G, van der Plicht J, Spurk M. 1998. IntCal98 radiocarbon age calibration, 24,000-0 cal BP. Radiocarbon 40(3):1041-83.

Xu XM, Trumbore SE, Zheng SH, Southon JR, McDuffe KE, Luttgen M, Liu JC. 2007. Modifying a sealed tube zinc reduction method for preparation of AMS graphite targets: reducing background and attaining high precision. Nuclear Instruments and Methods in Physics Research B 259(1):320-9. 